\title{
The Impact of Personality on Scholarly Performance in the Light of Intervening Job of Scholarly Motivation
}

\author{
Submitted 30/11/19, 1st revision 18/12/19, 2nd revision 23/01/20, accepted 09/02/20
}

\begin{abstract}
Almas Sabir ${ }^{1}$, Koauther Znaidi ${ }^{2}$, Nesrine Zouaoui Rejeb ${ }^{3}$
Abstract:

Purpose: This comparative study holistically assesses the effect of personality on scholastic motivation and scholarly performance.

Design/Methodology/Approach: The contribution and the relevant methodology are based on an educational motivation interceded the association between openness to experience and standards with scholarly performance. The research sample consists of students who willfully participated and they were approached to finish a personality poll (NEO-FFI), and a scholastic motivation survey (AMS-C 28 , included GPA and statistic information) on a pioneering critical comparative structural model.

Findings: Based on the implied arguments and yielded results, the article considers the interceding role of scholastic motivation about personality and performance. The nature of these relations, can be a point of takeoff to assist inquires about this issue.

Practical implications: Based on addressing its structural purposes, the study sheds a new light on the conscientiousness that predicts both intrinsic and extrinsic motivation. Earlier investigations show that there is a relationship between openness to involvement and insights.

Originality/Value: Although this study builds upon recent studies about character, motivation and different factors can affect scholastic performance that can be analyzed in future investigations as an innovative idea for the harmonization in this field.
\end{abstract}

Keywords: Openness to experience, personality, scholarly motivation and performance.

JEL code: $M 30$, M31.

Research type: Research article.

\section{Acknowledgments:}

This examination and coming about commitment are the consequence of instructive motivation intervened in the relationship between receptiveness to experience, and measures with insightful performance. Based on the alternate elements (e.g., IQ, learning moves close and biological variables) can influence academic execution that can be broken down in future examinations.

\footnotetext{
${ }^{1}$ Corresponding author,University of Hail,Saudi Arabia,College of Business

Administration,Department-Management, almas.sabir083@gmail.com

${ }^{2}$ University of Hail,Saudi Arabia,College of Business Administration,Department-

Management, znkaouther@yahoo.fr

${ }^{3}$ University of Tunis El Manar,ERMA Marketing Research Laboratory,Department-

Marketing, nesrine_zouaoui@yahoo.fr
} 


\section{Introduction}

Motivation originates from the Latin word moveo, which means to move, mix, shake, incite, or influence. Motivation responds to the inquiries: why do individuals act? for what reason do they carry on in a given way? for what reason do they proceed or end their practices? Motivation can be characterized as the procedure answerable for the commencement, power, and diligence of conduct. Thought processes are causes that produce certain impacts or activities (counting inaction). The wellspring of an individual's motivation might be characteristic, gotten from inner procedures, as well as outward, the after effect of outside powers. In a like manner, people can be incited to act by cognizant and nonconsciousness thought processes. Scholarly motivation alludes to the reason for practices that are here and there, identified with scholastic working and achievement, for example, how much exertion students set forth, how successfully they control their work, which tries they decide to seek after, and how steady they are when confronted.

To make the study more relevant only those studies were included which were published in the last few decades. In past research papers few dimensions of motivation were used to explain the different models of motivation theory in respect with scholarly performance and scholarly motivation, which has direct influence on individual's motivation. The novelty of this study lies in its theoretical framework where authors have attempted to come up with a construct having dimensions that directly or indirectly influences employee motivation (Sabir, 2017). A high educational level is desirable for not only the individual, but also their societies and associated economies. Educational success commonly leads to enhanced occupational status and high earnings (Pascarella and Terenzini, 1991), and societies with well-educated workforces tend to enjoy both greater economic growth (Hanushek and Woessmann, 2012) and social gains such as greater civic engagement and reduced crime rates (Bloom, Hartley and Rosovsky, 2007). This value accruing to educational success places a premium upon the identification of factors predicting academic performance. The following sections provide a brief historical overview of this research with emphasis on the role of personality in scholarly performance.

On the other hand, students are diverse over an immense scope of factors. At the end of the day, in addition to the fact that they are diverse in the wording of personality qualities, family foundations, age and sex, and so forth. They likewise display extraordinary mentalities and enthusiastic reactions to nature. Students have particular personality characteristics, which make them, arranged for having distinctive perspectives, and in this way for carrying on contrastingly in different social and instructive settings. Considering these distinctions can assist instructors in perceiving their students' individual contrasts. Indicators of scholarly accomplishment frequently lay on a continuum with intellectual measures, knowledge and mental capacities at one outrageous and non-psychological factor, for example, character qualities, financial status, and so forth. 


\section{Literature Review}

Despite the fact that after effects of concentrates by attempting to foresee scholastic accomplishment have yielded various outcomes, they have reliably called attention to the job of intellectual capacities and personality traits in scholastic accomplishment (Paunonen and Ashton, 2001). Educators have consistently asked whether individuals' personality traits can assist them with achieving higher scholastic accomplishment.

There is proof that personality attributes can foresee scholarly motivation and accomplishment (Costa and McCare, 1992). Crozier (1997) makes reference to motivation as a center attribute in the Big Five-factor model of a character realizing that faithful people are sorted out, dedicated, self-restrained, goal-oriented and persisting. Furthermore, motivation has a significant impact on a student's learning conduct and accomplishment (Vallerand et al., 1992). O'Connor and Paunonen (2007) consider three methods of reasoning for the assessment of character attributes as indicators of post-secondary students' scholarly accomplishment. To start with, there are social inclinations reflected in personality attributes that can influence certain propensities that affect scholastic accomplishment, for example, diligence, uprightness, loquacity. Second, while psychological capacity reflects what an individual can do, personality qualities reflect what an individual will do. Third, personality just as intellectual capability would foresee ensuing execution better in older students, particularly motivation related personality factors. In the recent research time and board the personality is the way to progress. It enables to assume responsibility for your life as opposed to following the progression of others. As you achieve all the more every day, settle on increasingly cool headed choices, and feel more in charge, individuals take note.

Pioneers in your business will come to you when they have to complete things. What is more, that not only personality attributes but expanded presentation helps place you in line for headway openings and openness to experience (Sabir, 2019). Caspi, Robert and Shiner (2005) shed light on the processes which can explain the relationships between personality traits and scholarly achievement in school or occupational settings. As per these authors, the relationship between personality and scholastic accomplishment might be one of appeal; for example, individuals pick situations which are predictable with their characters; when accomplishment criteria and personality attributes cover, personality and scholarly accomplishment might be legitimately related. A few thougths about have shown scholastic performance is emphatically connected with openness to experience pleasantness and extroversion and adversely connected with neuroticism (Laidra et al., 2007; Lounsbury et al., 2003a). These findings have not been reproduced in different examinations and no relationship has been accounted for between scholarly performance and extroversion (Bratko et al., 2006), neuroticism (Hair and Graziano, 2003), openness to experience, consciousness, extroversion (Wolfe and Johnson, 1995). Be that as it may, findings simultaneously point to a positive connection among scruples and 
scholastic accomplishment (Laidra et al., 2007), while a huge heap shows a positive relationship between scholastic accomplishment and good faith (Komarraju et al., 2009; Conard, 2009). Duckworth and Seligman (2005) place these variables' demonstration more insight factors. Extroversion is one of the Big Five character factors having the most fascinating association with scholastic execution. In spite of the fact that Melissa, Sampo and Panonon (2007) found a negative connection between these two factors, Chomoro and Furnham (2003a) detailed the turnaround. In light of past investigations, Dunsmore (2005) relates higher levels of extroversion to higher scholarly accomplishment among students, and to bring down scholarly performance at higher instructive levels. Such a model of results may reflect the change from the casual, interactional and class-situated condition at rudimentary colleges or schools to a progressively scholarly, study-situated and information based condition at college settings (Bernanthos, 2018).

The majority of the studies in the past explored personality trait with learning style (Elahi et al., 2013; Trompf and Brown, 2014), technology usage (Skues et al., 2014), academic performance (Feyter et al., 2012; Neuenschwander et al., 2013) and very sparsely discussed with scholarly motivation or used it as a mediator. These examinations don't give clear or steady proof relating the degree to which the personality related to scholastic motivation. Moreover, the personality characteristics and scholarly motivation affiliation ordinarily investigated with regards to class or students. Thus this examination plans to address this hole in the writing by looking at the effect of personality qualities on scholarly motivation among college students.

Improving the nature of training and venture on instructive and HR are viewed as compelling components making ready for a nation's inescapable improvement. Consequently, the improvement of students' scholastic accomplishment is likewise among the essential objectives of instructive arranging. It is through scholastic accomplishment students can completely realize their gifts and abilities in accordance with instructive objectives. In reality, scholarly accomplishment is considered as one significant criterion of instructive quality. On the other hand, students are diverse over an immense scope of factors. At the end of the day, in addition to the fact that they are diverse in the wording of personality qualities, family foundations, age, and sexual orientation, and so forth. They likewise show extraordinary frames of mind and enthusiastic reactions.

Students have particular personality attributes which make them arranged for having distinctive perspectives, and in this way for carrying on contrastingly in different social and instructive settings. Considering these distinctions can assist instructors in perceiving their students' individual contrasts. Indicators of scholarly accomplishment regularly lay on a continuum with subjective measures, knowledge and mental capacities at one extraordinary and non-psychological factor, (for example, personality attributes, financial status, and so on). In spite of the fact that consequences of concentrates attempting to anticipate scholarly accomplishment have yielded various outcomes, they have reliably brought up the job of intellectual 
capacities and personality attributes in scholastic accomplishment (Paunonen and Ashton, 2001). Teachers have consistently asked whether individuals' personality attributes can assist them with achieving higher scholastic accomplishment.

Scholarly accomplishment prominently affects the life of the students since it adjusts the students' mental inclination (Crystal et al., 1994; Cole, Martin, Peeke, Seroczynski and Fier, 1999) and goes about as an intend to accomplish fulfillment and prizes (Salmela-Aro and Tynkkynen, 2010). Nonetheless, the scholastic accomplishments emphatically rely upon the individual motivation level (Komarraju, Karau and Schmeck, 2009). The qualities, which can influence the understudy scholastic motivation, ought to be distinguished during their school life with the goal that they ought to be changed from time to time and improves their scholastic advancement (Zuffianò et al., 2013: Suharno and Dini, 2018).

\subsection{Personality Attributes}

The big five personality model as a general scientific categorization in a wide scope of behavioral and mental research has been a point of reference. This model comprises of five moderately autonomous measurements: extraversion, neuroticism, principles or conscientiousness, agreeableness or pleasantness, and openness to experience. In this article, we look at openness to experience and good faith. Openness envelops a wide scope of qualities (McCrae and Costa, 1985). This attribute is identified with being inventive, insightful, inquisitive, masterful, and being keen on a wide scope of issues. Then again scruples as one of the dependable elements of the big five, manages discretion, steadiness, and being solid, composed, capable, planful, and aware of mindful details. In past literature, various personality models have been proposed (Eysenck and Eysenck, 1975) but the big fivepersonality model acts as the most acceptable model in the fields of psychological and behavioral research (Hazrati-Viari et al., 2012). The big five personality trait model was given by Costa and McCrae (1992) and considered as a strong framework for understanding the association between different types of personalities and academic behaviors (Poropat, 2009).

Personality traits mirror individuals' trademark examples of contemplations, emotions, and practices. Personality traits infer consistency and strength - somebody who scores high on a particular attribute like extraversion is relied upon to be agreeable in various circumstances and after some time. Along these lines, quality brain research lays on the possibility that individuals contrast from each other as far as where they remain on a lot of fundamental attribute measurements that continue after some time and across circumstances. The most generally utilized arrangement of characteristics is known as the Five-Factor Model. This framework incorporates five wide characteristics that can be recalled with the abbreviation OCEAN: Openness, Conscientiousness, Extraversion, Agreeableness, and Neuroticism. Every one of the significant qualities from the big five can be partitioned into aspects to give all the more fine-grained investigation of somebody's character. 
Also, some attribute scholars contend that there are different characteristics that cannot be totally caught by the Five-Factor Model. Pundits of the characteristic idea contend that individuals don't act reliably starting with one circumstance then onto the next and that individuals are very affected by situational powers. Accordingly, one significant discussion in the field concerns the general intensity of individuals' qualities versus the circumstances wherein they wind up as indicators of their conduct.

\subsection{Scholarly Motivation}

Scholarly motivation alludes to the student wants or eagerness identified with scholastic subjects (Wigfield and Eccles, 2002). Usher and Morris (2012) characterized scholarly motivation is by one way or another identified with the students scholarly working and achievement. It may be characterized as how much exertion the student advances to control his/her work, which exercises he/she needs to seek after. Ricard and Pelletier (2016) characterized scholastic motivation as a factor that affects the individual's readiness to go to class and get a degree. On the off chance that a student is inherently spurred, he/she will go to the college to adapt new thoughts or things. Be that as it may, if the student is outwardly roused, he/she played out a movement because of some purpose behind for example the students' visits school in light of the fact that the position he/she needs to rely upon this training. Motivation happens when the students does not have the foggiest idea about the motivation behind why he/she is going to class.

Deci and Ryan (1985) in the Self-Determination Theory (SDT) propose three kinds of motivation: intrinsic (natural), extrinsic (outward), and motivation. "This hypothesis centers around types, as opposed to simply sum, of motivation, giving specific consideration to self-sufficient motivation, controlled motivation, and motivation as indicators of execution, social, and prosperity results" (Deci and Ryan, 2008). At the point when individuals are inherently spurred they experience intrigue, enjoyment, delight, and feel skilled and self-determined. Thusly, extrinsically roused people see their conduct as an outcome of outside elements. Mori and Gobel (2006) contend that natural worth alludes to the happiness that assignment commitment achieves through extraneous utility worth alludes to the helpfulness of the undertaking as far as a person's future objectives. The third kind of motivation, "motivation", is portrayed as discernable detachment among activities and results. Motivated individuals do not think about any connection between exertion and fulfillment of a prize. They credit accomplishment to karma or characteristic capacities (luck or natural abilities) and reason that accomplishment is not earned through efforts (Deci and Ryan, 1985).

\subsection{How Motivation Affects Learning and Behavior}

Motivation effectively affects students' learning and conduct. In the first place, motivation coordinates conduct toward specific objectives. Motivation decides the 
particular objectives toward which individuals endeavor; consequently, it influences the decisions students to make. For instance, regardless of whether to try out a craftsmanship class or material science, whether to go to a school ball game during the week or complete a task that is expected the following day. Motivation additionally prompts expanded exertion and vitality. Motivation decides if an understudy will seek after an undertaking (even a troublesome one) with energy or a dull frame of mind. Motivation expands the commencement and tirelessness of exercises. Motivation will expand students' time on task and is additionally a significant factor influencing their learning and accomplishment.

Motivation improves psychological preparation. Motivation really influences what and how data is prepared in light of the fact that roused students are bound to focus and attempt to comprehend the material rather than basically making a cursory effort of learning in a shallow way. Motivation figures out what outcomes are strengthening and rebuffing. For instance, students with an elevated level of motivation for homeroom accomplishment and high GPAs are fortified by getting an evaluation of 'A' and they will feel rebuffed in the event that they get an evaluation of 'F.' At last, motivation prompts improved execution. Everything that we have quite recently examined - exertion, inception, industriousness, subjective preparing and the effect of results - prompts improved execution.

\subsection{The Present Examination}

There is exact proof demonstrating that both personality and scholarly motivation as two related factors are significant indicators of scholastic performance. The present investigation is intended to inspect a potential intervening job of scholarly motivation in the connection between personality and scholastic performance dependent on past discoveries. Based on hypothetical suspicions and earlier observational outcomes referenced above, it was theorized that conscientiousness and openness to experience are the primary characteristics of personality affecting scholarly performance. We anticipated that this impact should be directed by intrinsic and extrinsic motivation.

Along these lines, the reason for this examination is to analyze the effect of personality qualities in framing scholarly motivation among college students. The purpose behind picking students as an example of its social decent variety. Culture broadens as far as qualities, dialects, standards, and customs (Sarki et al., 2012). Inside each sub-culture, they have their own standards and conduct desires, which direct which personality characteristics can be considered significant. One quality, which is viewed as positive in one culture, should think about negative in the other. In this way, this assorted variety may influences the students' personality and some may have one sort of personality attribute more grounded than the other does and simultaneously, the diverse social miens may likewise influence their motivation towards learning. Along these lines, the motivation behind this investigation is to 
break down the relationship between the character attribute and scholarly motivation in the business college students.

\section{Research Methodology}

\subsection{Respondents and Data Assortment}

The dataset was gathered from 400 students. From all the surveys conveyed, 358 were returned. 141 surveys were incomplete and hence cannot take them for further calculations. In the wake of being screened for ease of use and analysis, 217 reactions were seen as complete and legitimate for investigation purposes with mean $=23.03$ and standard deviation $=3.146$. Respondents were approached to finish the NEO and AMS-C surveys in college and took part on a deliberate premise. This investigation features the significance of personality attribute in framing scholastic motivation of the students and furthermore helps the instructive organizations and instructors to create systems likewise.

\subsection{Study Measures}

\subsubsection{Scholarly motivation}

Applying self-determination theory (SDT) to educational settings has proven to be a productive undertaking. In this article SDT is ued for further analysis and results. Self-determination theory (SDT) is a macro theory of human motivation and personality that concerns people's inherent growth tendencies and innate psychological needs. It is concerned with the motivation behind choices people make without external influence and interference.

The self-determination theory has been operationalized through the Academic Motivation Scale (AMS-C; Vallerand et al., 1992). Hence, to assess student's scholastic motivation, this poll was utilized which is considered as one of the most proper scholastic motivational scales accessible. The AMS-C incorporates seven subscales which measure three kinds of intrinsic motivation (natural motivation to know, to achieve things, and to encounter incitement), three kinds of extrinsic motivation (external, introjected, and recognized guideline), and amotivation. High scores in one of the seven zones show the person's quality of scholastic motivation and a craving to seek after postsecondary training. This survey contains 28 things that are replied on a 7-point Likert scale.

\subsubsection{Personality}

Personality attributes were evaluated with the NEO FFI (Costa and McCrae, 1992). This is a short form of the NEO PI-R and evaluates the personality measurements of neuroticism (low enthusiastic strength), extraversion, and openness to experience, appropriateness, and good faith. Things include inquiries concerning commonplace practices or responses and are replied on a five-point Likert-type scale, going from "strongly disagree" to "strongly agree". People were approached to portray 
themselves over a scope of 60 things with 12 inquiries for each factor. There is an extraordinary literature of exact writing over the previous decade giving proof of its simultaneous, build, joined, convergent, divergent, incremental, and predictive validity (Chamorro-Premuzic and Furnham, 2003).

\subsubsection{Scholastic performance}

Scholastic performance was surveyed by Grade-point-average (GPA). Students revealed their GPA from their last two semester's average.

\subsubsection{Data investigation}

In this research SEM technique is also used. Structural equation modeling is a multivariate statistical analysis technique that is used to analyze structural relationships. This technique is the combination of factor analysis and multiple regression analysis, and it is used to analyze the structural relationship between measured variables and latent constructs.

This examination also applied the SEM technique to methodically research how various elements impact student's scholastic performance. To evaluate the relations between scholarly self-idea what is more feelings in explicit areas, SEM was utilized to take into consideration the disattenuated connections between the factors under scrutiny to be assessed. To address for potential inclination related with class enrollment, SEM investigations were likewise led with AMOS utilizing the perplexing example choice.

\section{Results}

Table 1 displays the mean qualities, standard deviations, and correlations between openness, conscientiousness, extrinsic motivation, intrinsic motivation, and GPA. As can be seen all of correlations with the exception of intrinsic motivation and extrinsic motivation with GPA are significant.

Table 1. Correlations between openness, conscientiousness, extrinsic motivation, intrinsic motivation, and GPA

\begin{tabular}{|c|c|c|c|c|c|c|c|}
\hline & $\mathbf{M}$ & SD & 1 & 2 & 3 & 4 & 5 \\
\hline Openness to experience & 27.3 & 6.9 & 1 & & & & \\
\hline Conscientiousness & 34.1 & 7.5 & $21 * *$ & 1 & & & \\
\hline Extrinsic motivation & 28.3 & 6.1 & $.17 * *$ & $.21 * *$ & 1 & & \\
\hline Intrinsic motivation & 54.0 & 9.2 & $.37 * *$ & $.34 * *$ & .05 & 1 & \\
\hline GPA & 17.3 & 2.1 & $18^{* * *}$ & $.08 *$ & .05 & $27 * *$ & 1 \\
\hline
\end{tabular}

The reason for the present path examination was to estimate the general relative contributions of openness and conscientiousness in the clarification of the scholastic motivation variable. To test our model and to show how personality components may have a backhanded impact upon scholastic performance, we figure few path models. 
The last model's records are displayed in this article. Standardized path coefficients and fit records permit estimation of causal connections between factors. The model was determined with paths from conscientiousness and openness to the two features of the motivation and with ways from extrinsic and intrinsic motivation to GPA. Change files likewise recommended that including a path among openness and conscientiousness would fundamentally improve the fit.

Six integrity of fit files were utilized to assess the sufficiency of the model fit:

1. The chi squared $\left(\chi^{2}\right)$ test;

2. The comparative fit index (cfi);

3. The goodness of- fit index (gfi);

4. The relative fit index (rfi);

5. The tucker-lewis index (tli);

6. The Root Mean Square Error of approximation (RMSEA).

The structural model demonstrated solid match to the information which are as follows:

1. Chi-square $=3.709$;

2. $\mathrm{df}=3$;

3. $\mathrm{p}=.295$;

4. RMSEA = .033;

5. $\mathrm{GFI}=.993$;

6. $\mathrm{TLI}=.981$;

7. $\mathrm{CFI}=.994$;

8. RFI $=.909$.

All paths in the structural model, with the exception of the path between extrinsic motivation and GPA were noteworthy. Openness to experience was a more grounded indicator than honesty or conscientiousness to scholarly motivation. Yet, this variable could just foresee intrinsic motivation. The connection between openness and futhermore extrinsic motivation was not huge. The principles factor was essentially identified with both inherent what's more, extrinsic motivation, yet the quality of relationship was lower than openness to experience.

\section{Discussion and Conclusion}

It may be inferred that conscientiousness predicts both intrinsic and extrinsic motivation. Crozier (1997) contends that reliable students are probably going to fulfill time constraints for assignments, that they will complete errands instead of leave them deficient, that they will place a specific measure of exertion into an errand, that they can put forth a concentrated effort without persistent supervision, etc. Openness to experience anticipated just intrinsic motivation and consequently scholastic accomplishment proposing that the individuals who are high on openness will in general be mentally inquisitive, keen, savvy, stylish, and intrigued. These characteristics can exhibit why students who are high in transparency perform better. 
For instance being intrigued and keen, they want to increase profound comprehension of numerous things. This premium can situate to new systems of learning and new scholarly issues bring about scholastic accomplishment. Having past research as a primary concern, earlier looks into demonstrate that there is a connection between openness to experience and knowledge. For example ChamorroPremuzic and Furnham (2008) proposed the "venture" job of openness to experience as a determinant of higher IQ, contend that IQ is independently influenced by fluid intelligence insight and openness to experience and influenced profound realizing, which thus prompted higher evaluations.

To conclude, educators can look for the low/high-accomplishment causal factors in motivational and personality characteristics. The significance of these individual contrasts and attempting to remember them ought to likewise be considered. Notwithstanding personality and motivation, different factors (e.g., IQ, learning draws near and natural factors) can impact scholarly performance that can be inspected in future examinations. By investigating the intervening job of scholastic motivation in relations to personality and performance added another perspective to these relations. The idea of these relations, be that as it may, can be a point of takeoff for further research around there.

In light of hypothetical suspicions and observational investigations on personality (conscientiousness and openness to experience) and impact on scholarly motivation and accomplishment (e.g., Costa and McCrae, 1992; Grozier, 1997; Komarraju et al., 2009; Clark and Schroth, 2010), we speculated that the connection between personality and scholarly performance interceded by personality and extrinsic motivation. True to form, the outcomes demonstrated that good faith and openness to experience can anticipate scholarly performance (Komarraju and Karau, 2005), recommending that students who score high in conscientiousness and openness will be increasingly effective at college. The outcomes additionally affirmed that motivation assumes an interceding job in relations between personality qualities and scholastic performance.

As it is clear from the investigation, that the personality qualities assume a significant job in molding scholastic motivation, the teacher should structure their class exercises and assignments in such a way which builds them. For example, to build good faith the assignments ought to be acknowledged in little parts, transparency ought to be improved by giving students the stage to share their thoughts. They ought to likewise know to what degree every personality quality ought to be urged to improve the scholarly motivation. Every one of these measures bring about expanded motivational level and readiness to accomplish scholarly performance.

The instructive establishments ought to likewise give preparing to the educators on the most proficient method to oversee the distinctive personality's attributes students. Likewise, association ought to furnish students with such an adjusted stage 
where they could without much of a stretch use their personality characteristics, remain roused and at last improve their scholarly motivation. The foundations and the instructors should make their condition in such a way, that matches with students' personality attributes as it prompts scholastic motivation.

\section{References:}

Bernanthos, B. 2018. Employees' Performance in Islamic Banking. European Research Studies Journal, 21(1), 31-42.

Bloom, D.E., Hartley, M., Rosovsky, H. 2007. Beyond private gain: The public benefits of higher education. In J.J. Forest and P.G. Altbach (Eds.), International handbook of higher education, vol. 18, 293-308, doi: 10.1007/978-1-4020-4012-2_15.

Bratko, D., Chamoro, T., Saks, Z. 2006. Personality and school performance: Incremental validity of selfand peer-ratings over intelligence. Personality and Individual Differences, 41, 131-142.

Caspi, A., Roberts, B.W., Shiner, R.L. 2005. Personality development: Stability and change. Annual Review of Psychology, 56, 453-484.

Chamorro-Premuzic, T., Furnham, A. 2003. Personality predicts academic performance: Evidence from two longitudinal university samples. Journal of Research in Personality, 37, 319-338.

Chamorro-Premuzic, T., Furnham, A. 2008. Personality, intelligence and approaches to learning as predictors of academic performance. Personality and Individual Differences, 44, 1596-1603.

Cole, D.A., Martin, J.M., Peeke, L.A., Seroczynski, A.D., Fier, J. 1999. Children's over and underestimation of academic competence: A longitudinal study of gender differences, depression and anxiety. Child Development, 70, 459-473.

Conard, M. 2006. Aptitude is not enough: How personality and behavior predict academic performance. Journal of Research in Personality, 40, 339-346.

Costa, P.T.Jr., McCrae, R.R. 1992. NEO PI-R professional manual: Revised NEO PI-R and NEO-FFI. Florida, Psychological Assessment Resources, Inc.

Crozier, W.R. 1997. Individual learners: Personality differences in education. London: Routledge.

Crystal, D.S., Chen, C., Fuligni, A.J., Stevenson, H.W., Hau, C.C., Ko, H.J. 1994. Psychological maladjustment and academic achievement: A cross-cultural study of Japanese, Chinese and American high school students. Child Development, 65, 738-753.

Deci, E.L., Ryan, R.M. 1985. Intrinsic motivation and self-determination in human behavior. New York: Plenum Press.

Deci, E.L., Ryan, R.M. 2008. Self-determination theory: A macro theory of human motivation, development, and health. Canadian Psychology, 49, 182-185.

Dunsmore, J.A. 2005. An investigation of the predictive validity of broad and narrow personality traits in relation to academic achievement. A dissertation Ph.D., University of Tennessee, Knoxville.

Elahi, M., Braunhofer, M., Ricci, F., Tkalcic, M. 2013. Personalitybased active learning for collaborative filtering recommender systems. In Congress of the Italian Association for Artificial Intelligence, 360-371. Springer International Publishing.

Eysenck, H.J., Eysenck, S.B.G. 1975. Manual of the Eysenck Personality Questionnaire (junior and adult). Hodder and Stoughton. 
Furnham, A., Zhang, J., Chamoro, T. 2006. The relationship between psychometric and selfestimated intelligence, creativity, personality and academic achievement. Imagination, cognition and personality, 25(2), 119-145.

Hair, E.C., Graziano, W.G. 2003. Self-esteem, personality and achievement in high school: A prospective longitudinal study in texas. Journal of Personality, 71, 971-994.

Hanushek, E.A., Woessmann, L. 2012. Do better schools lead to more growth? Cognitive skills, economic outcomes, and causation. Journal of Economic Growth, 17(4), 267321. doi: 10.1007/s10887-012-9081-x.

Komarraju, M., Karau, S.J. 2005. The relationship between the Big Five personality traits and academic motivation. Personality and Individual Differences, 39, 557-567.

Komarraju, M., Karau, S.J., Schmeck, R.R. 2009. Role of the Big Five personality traits in predicting college students' academic motivation and achievement. Learning and Individual Differences, 19, 47-52.

Laidra, K., Pullmann, H., Allik, J. 2007. Personality and intelligence as predictors of academic achievement: Across-sectional study from elementary to secondary school. Personality and Individual Differences, 1-11.

Lounsbury, J.W., Tatum, H., Gibson, L.W., Park, S.H., Sundstorm, E., Hamrick, F., Wilburn, D. 2003. The development of a big five adolescent personality scale. Psychoeducational assessment, 21, 111-133.

McCrae, R.R., Costa, P.T.Jr. 1985. Openness to experience. In R. Hogan \& W.H. Jones (Eds). Perspectives in personality: Theory, measurement, and interpersonal dynamics, 145-177. Greenwich, CT: JAI Press

Melissa, C., Sampo, C., Paunonen, V. 2007. Big five personality predictors of postsecondary academic performance. Personality and Individual Differences, 43, 437-448.

Mori, S., Gobe, P. 2006. Motivation and gender in the Japanese EFL classroom. System, 3, 194-210.

Neuenschwander, R., Cimeli, P., Röthlisberger, M., Roebers, C.M. 2013. Personality factors in elementary school children: Contributions to academic performance over and above executive functions? Learning and individual differences, 25, 118-125.

O’Connor, M.C., Paunonen, S.V. 2007. Big Five personality predictors of post-secondary academic performance. Personality and Individual Differences, 43, 971-990.

Pascarella, E.T., Terenzini, P.T. 1991. How college affects students: Findings and insights from twenty years of research. San Francisco, CA, Jossey-Bass.

Paunonen, S.V., Ashton, M.C. 2001. Big five predictors of academic achievement. Journal of Research in Personality, 35, 78-90.

Ricard, N.C., Pelletier, L.G. 2016. Dropping out of high school: The role of parent and teacher self-determination support, reciprocal friendships and academic motivation. Contemporary Educational Psychology, 44, 32-40.

Sabir, A. 2017. Motivation: Outstanding Way to Promote Productivity in Employees. American Journal of Management Science and Engineering, Vol. 2, No. 3, 35-40. doi: 10.11648/j.ajmse.20170203.11.

Sabir, A. 2019. How Good Is Your Time Management? Budapest International Research and Critics Institute-Journal (BIRCI-Journal), Volume 2, No 4, November, 682-697 eISSN: 2615-3076 (Online), p-ISSN: 2615-1715 (Print), DOI:https://doi.org/10.33258/birci.v2i4.686. 
Salmela-Aro, K., Tynkkynen, L. 2010. Trajectories of life satisfaction across the transition to post-compulsory education: Do adolescents follow different pathways? Journal of Youth and Adolescence, 39, 870-881.

Sarki, I.H., Bhutto, N.A., Arshad, I., Khuhro, R.A. 2012. Impact of Pakistani university student's cultural values and lifestyles on meaning of brands. Interdisciplinary Journal of Contemporary Research in Business, 3(9), 643-654.

Suharno, P., Dini, I. 2018. The Influence of Work Stress, Working Cost, Compensation and Work Discipline on Employee' Productivity. International Journal of Economics and Business Administration, 6(4), 62-75.

Trompf, L., Brown, C. 2014. Personality affects learning and trade-offs between private an social information in guppies, Poecilia reticulata. Animal Behaviour, 88, 99-106.

Vallerand, R.J., Pelletier, L.G., Blais, M.R., Briere, N.M., Senecal, C., Vallieres, E.F. 1992. The academic motivation scale: A measure of intrinsic, extrinsic, and amotivation in education. Educational and Psychological Measurement, 52, 1003-1017.

Usher, E.L., Morris, D.B. 2012. Academic motivation. In Encyclopedia of the Sciences of Learning, 36-39. Springer, USA.

Wigfield, A., Eccles, J.S. 2002. Students' motivation during the middle school years. In J. Aronson (Ed.), Improving academic achievement: Impact of psychological factors on education, 159-184.

Wolfe, R.N., Johnson, S.D. 1995. Personality as a predictor of college performance. Educational and Psychological Measurement, 55, 177-185.

Zuffianò, A., Alessandri, G., Gerbino, M., Kanacri, B.P.L., Di Giunta, L., Milioni, M., Caprara, G.V. 2013. Academic achievement: The unique contribution of selfefficacy beliefs in self-regulated learning beyond intelligence, personality traits, and self-esteem. Learning and Individual Differences, 23, 158-162. 